\title{
Modelling and Motion Control of BLDC motor for Pan tilt Platform.
}

\author{
IMRAN S. SARWAR \\ Department of Mechatronics and Biomedical Engineering \\ Air University, Islamabad \\ Service Road E-9 / E-8, Islamabad, Pakistan, 44000 \\ PAKISTAN \\ imran.sarwar@au.edu.pk https://scholar.google.com/citations?user=xLkXyxMAAAAJ\&hl=en
}

\begin{abstract}
The usage of Brush-Less Direct Current (BLDC) motor has been increased in the industry especially in the field of Aerospace and electric bikes. The requirements for motion control were generated from the human eye features. The settling time and $\%$ overshoot were the desired features and design parameters. Based on desired features, values of $\xi$ and $\omega_{\mathrm{n}}$ were found. The root-locus technique was applied to the uncompensated and compensated system, the results were not satisfactory. The \% overshoot was very high, and the steady-state error was also very high. The state feedback controller was applied to the system. The \% overshoot was controlled successfully but the steady-state error was still very high. To reduce the steady-state error to zero the integral control was applied. The comparison of results is presented in tabular form in the last section.
\end{abstract}

Key-Words: - State feedback controller, Integral Control, Dynamics, Actuating System, Brushless DC motor, Mechatronics, Pan tilt Platform.

Received: November 3, 2020. Revised: March 5, 2021. Accepted: March 21, 2021. Published: April 8, 2021.

\section{Introduction}

DC motors had been used in the commercial and defence systems for last 150 years. They are precisely controllable, that's why they are used in medical, defence and other industries, other type of actuators were not used in industry because they needed a special setup. DC motors are efficient and have high starting torque. As torque is increased using gearbox and speed decreases by same factor, most of motor manufacturing companies have the gearbox integrated with motors. Thus, high efficiency motors with gearboxes even do not require periodic maintenance, but with a such characteristics the DC motors have some deficiencies such as mechanical wear outs, acoustic noise, sparkling and brushes. These effects have some of the problems that are required to overcome. The result of the research work carried on motors is synchronous DC motor with brushless commutators. So, current research work has been tailored towards developing Brush-Less Direct Current (BLDC) motors. The usage of BLDC motors is increasing rapidly in industries such as electric motor bikes and actuators in aeronautics etc. The advantages of BLDC motor over conventional DC motor are as follows: better speed versus torque characteristics, high efficiency, high dynamic response, long operating life, noiseless operation, higher speed ranges and low maintenance. The low maintenance in terms of brush cleaning, which exists in the brushed DC motor. One of the major advantages is that the BLDC motor has ratio of torque delivered to the physical size of the BLDC motor is higher, therefore it is more useful in terms of space and weight consideration.

The BLDC motors come in different phases, for example single and three phase. Most commonly used BLDC motor is three phase. In this paper, a study will be considered on how the BLDC motors could be compensated in terms of control and stability. In the next section a mathematical model of DC and BLDC motor is presented. In such a manner that design of basic DC motors tailored towards developing a BLDC motor model. After determining the model, the stability of BLDC motor is analysed using the data from [1]. The controller is designed using the model of BLDC motor developed in the paper. The parameters are obtained from [1] and [5] datasheet of BLDC motor. In the next section the mathematical model of DC motor is discussed and after that BLDC motor model is presented in this paper. Brushless motors are used in industrial positioning and actuation applications. For 
assembly robots, brushless stepper or servo motors are used to position a part for assembly or a tool for a manufacturing process, such as welding or painting. Brushless motors can also be used to drive linear actuators. Despite the need of a complex motor controller, the simplicity of construction of BLDC motors offers several inherent advantages not provided with brushed DC motors in terms of low inertia, high torque and a very wide speed range. BLDC motors require less overall maintenance due to lack of brushes. They operate effectively at all speeds with rated load and have high efficiency. BLDC motors have reduced size with far superior thermal characteristics and higher speed ranges [12].

\section{Mathematical Model of DC motor}

Electric motors are the most widely used electromechanical actuators. They can either be classified based on functionality or electromagnetic characteristics. The differences in electric motors are mainly in the rotor design and the method of generating the magnetic field. Common construction components of electric motors are stator, field coil, rotor, armature, air gap, brush and slip rings.[2] The equivalent circuit of DC motor such as shunt, series and compound motor etc can be represented by following fig. 1. Using the basic circuit theory, the equivalent inductance and equivalent resistance can be found such as in case of series motor resistances and inductors are connected in series, so resistance are simply added and similarly inductors are added. Thus, equivalent resistance and equivalent inductance are found.

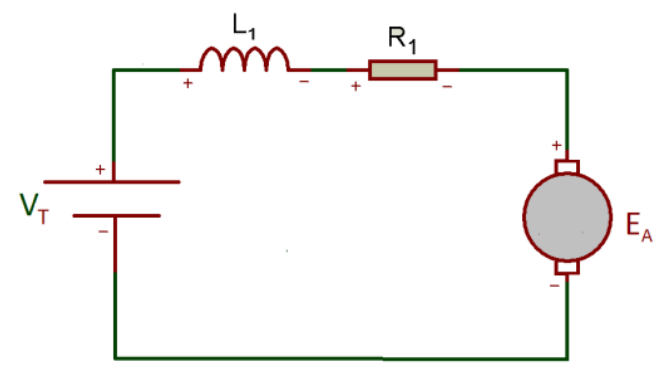

Fig. 1 Equivalent Circuit of DC motor without torque and speed

The basic component in the above fig. 1 are equivalent resistance $R_{1}$ and equivalent inductance $L_{1}$. There is a back emf represented with symbol $E_{A}$.

$V_{T}=R_{1} i+L_{1} \frac{d i}{d t}+E_{A}$
At steady state $\frac{d i}{d t}=0$

Thus equation (1) reduces to

$V_{T}=R_{1} i+E_{A}$

Thus, for non-steady state $\left(\frac{d i}{d t} \neq 0\right)$, equation (1) is rearranged to make provision for the back emf as follows

$E_{A}=-R_{1} i-L_{1} \frac{d i}{d t}+V_{T}$

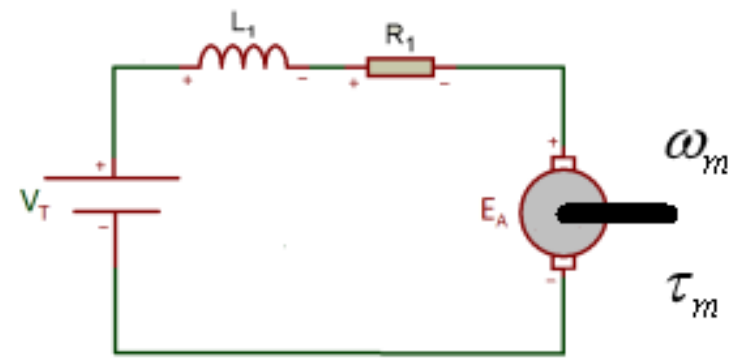

Fig. 2 Equivalent Circuit of DC motor with motor torque and speed

Here, $V_{T}$ is supplied/terminal DC voltage and $i$ is the current flowing in the circuit shown in the Fig. 2.

Similarly, consider the mechanical properties of DC motor, from the newton's $2^{\text {nd }}$ law of motion. The mechanical components and their effect are shown in fig. 2. The product of inertia (due to load and motor shaft) $J$ and the rate of change of angular velocity $\frac{d \omega_{m}}{d t}$ is equal to sum of the all the torques.

$\sum \tau_{i}=J \frac{d \omega_{m}}{d t}$

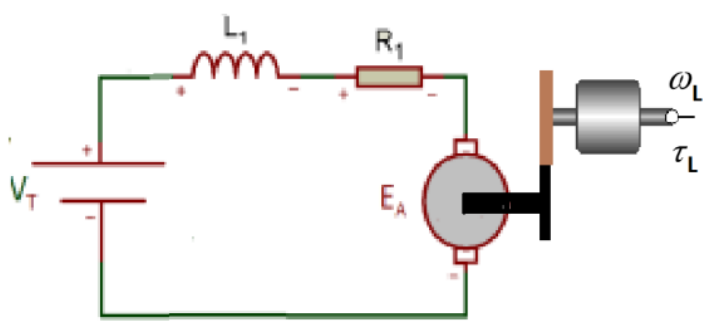

Fig. 3 Equivalent Circuit of DC motor with gear and load (load torque and speed)

$\tau_{m}=-k_{f} \omega_{m}+J \frac{d \omega_{m}}{d t}-\tau_{L}$ 
Here $k_{f}$ is friction constant, $\tau_{m}$ is motor torque and $\tau_{L}$ is load torque. The motor torque and back emf could be written as follows

$E_{A}=k_{m} \omega_{m}$ and $\tau_{m}=k_{t} i$

Here $k_{m}$ is constant of back emf and $k_{t}$ is torque constant. Using equation (3) and (6) got the result as follows

$\frac{d i}{d t}=-\frac{R_{1}}{L_{1}} i-\frac{k_{m}}{L_{1}} \omega_{m}+\frac{1}{L_{1}} V_{T}$

Following result is obtained using the equation (5) and (6)

$\frac{d \omega_{m}}{d t}=\frac{k_{t}}{J} i-\frac{k_{f}}{J} \omega_{m}+\frac{1}{J} \tau_{L}$

By taking the Laplace of equation (7) and (8), the following equations are obtained, assuming all initial condition are zero.

$$
\begin{aligned}
& s I(s)=-\frac{R_{1}}{L_{1}} I(s)-\frac{k_{m}}{L_{1}} \omega_{m}(s)+\frac{1}{L_{1}} V_{T}(s) \\
& s \omega_{m}(s)=\frac{k_{t}}{J} I(s)-\frac{k_{f}}{J} \omega_{m}(s)+\frac{1}{J} T_{L}(s)
\end{aligned}
$$

In the fig. 3 two spur gear are attached with each other. Spur gears are the most common type of gears. They have straight teeth and are mounted on parallel shafts. The torque relationship is as follows

$\tau_{L}=\frac{n_{2}}{n_{1}} \tau_{m}$

Here $n_{1}$ is number of teeth derive gear and $n_{2}$ is number of teeth of driven gear. Put Laplace of the equation (11) into equation (10) to obtain equation as follows

$$
\begin{aligned}
& s \omega_{m}(s)=\frac{k_{t}}{J}\left(1+\frac{n_{2}}{n_{1}}\right) I(s)-\frac{k_{f}}{J} \omega_{m}(s) \\
& \left(s+\frac{k_{f}}{J}\right) \omega_{m}(s)=\frac{k_{t}}{J}\left(\frac{n_{1}+n_{2}}{n_{1}}\right) I(s) \\
& I(s)=\frac{n_{1}\left(J s+k_{f}\right)}{k_{t}\left(n_{1}+n_{2}\right)} \omega_{m}(s)
\end{aligned}
$$

Substitute $I(s)$ from equation (14) into equation (9)

$$
\begin{gathered}
\left(n_{1}\left(s L_{1}+R_{1}\right)\left(J s+k_{f}\right)+k_{m} k_{t}\left(n_{1}+n_{2}\right)\right) \omega_{m}(s) \\
=k_{t}\left(n_{1}+n_{2}\right) V_{T}(s)
\end{gathered}
$$

The resulting transfer function is

$\frac{\omega_{m}(s)}{V_{T}(s)}=\frac{k_{t}\left(n_{1}+n_{2}\right)}{\left(n_{1}\left(s L_{1}+R_{1}\right)\left(J s+k_{f}\right)+k_{m} k_{t}\left(n_{1}+n_{2}\right)\right)}$

$G(s)=\frac{k_{t}\left(n_{1}+n_{2}\right)}{n_{1} L_{1} J s^{2}+n_{1}\left(R_{1} J+L_{1} k_{f}\right) s+n_{1} R_{1} k_{f}+k_{m} k_{t}\left(n_{1}+n_{2}\right)}$

Consider the following assumptions to simplify the equation (16) as follows

a) Friction constant $k_{f}$ is so small that it tends to 0 .

b) The product of $R_{1}$ and $J$ is greater than product of $L_{1}$ and $k_{f} \cdot\left(R_{1} J>>L_{1} k_{f}\right)$

c) Similarly, the $k_{m} k_{t}>>R_{1} k_{f}$.

Using the assumptions, the transfer function is simplified and given below

$G(s)=\frac{k_{t} \frac{\left(n_{1}+n_{2}\right)}{n_{1}}}{L_{1} J s^{2}+R_{1} J s+k_{m} k_{t} \frac{\left(n_{1}+n_{2}\right)}{n_{1}}}$

So, the equation (17) can be expressed in terms of time constants of mechanical structure and electrical circuit. The mechanical and electrical time constant are as follows

$\tau_{\text {mech }}=\frac{R_{1} J}{k_{m} k_{t}}$

$\tau_{\text {elecl }}=\frac{L_{1}}{R_{1}}$

Using the equation (17), (18) and (20), the transfer function in equation (17) will become as follows

$G(s)=\frac{\frac{n}{k_{m}}}{\tau_{\text {mech }} \tau_{\text {elect }} s^{2}+\tau_{\text {mech }} s+n}$

Here $n=\frac{\left(n_{1}+n_{2}\right)}{n_{1}}$

The above transfer function represents the DC motor with gears and load applied.

\section{Mathematical Model of BLDC motor}

Like single-phase synchronous motor but with multiple stator windings for smoother operation. Essentially a poly-phased AC synchronous motor but using electronic commutation to match rotor and stator magnetic fields. Electronic commutation enables using a DC source to drive the synchronous motor. [2] 
The difference between the DC motor and Brushless DC motor is DC motor has brushes and they are attached to its stator; brushes are not part of BLDC motor. Unlike the DC motors the commutation of the BLDC motor could be done by electronic control.[3] In the BLDC motor, the stator windings are energised in the sequence for the motor to rotate. BLDC motor require less maintenance due to the absence of the brushes. It has long life and high efficiency no voltage drops across brushes.

The mathematical model of BLDC motor is quite different from DC motor. The major thing is the phases involved which affects the overall results of the BLDC model. The phases peculiarly affect the resistance and the inductance of the 3 phase BLDC motor arrangement as shown in fig. 4 .

The difference will affect the mechanical and electrical time constants as they are directly affecting the poles of BLDC motor. So, these time constants will determine the system behaviour. For the mechanical time constant equation (18) becomes as follows

$$
\tau_{\text {mech }}=\sum \frac{R_{1} J}{k_{m} k_{t}}=\frac{J \sum R_{1}}{k_{m} k_{t}}
$$

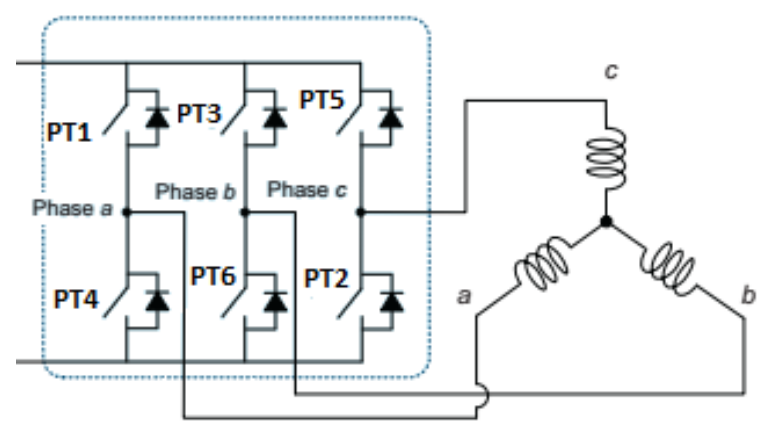

(a)

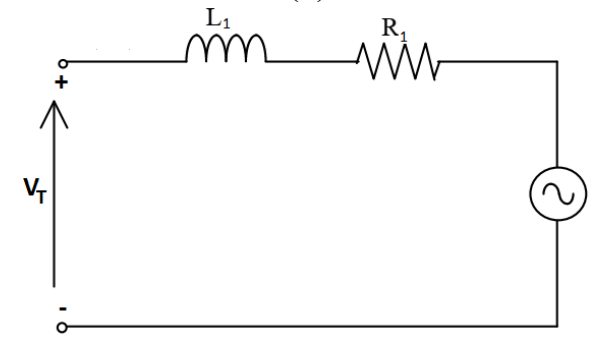

(b)

Fig. 4 (a). BLDC motor attached with driver (b). Dynamic per phase equivalent circuit of BLDC motor

The electrical time constant (19) becomes as follows

$$
\tau_{\text {elecl }}=\sum \frac{L_{1}}{R_{1}}=\frac{L_{1}}{\sum R_{1}}
$$

Therefore, symmetrical arrangement and 3 phases, the mechanical time constant in equation (21) becomes as follows

$\tau_{\text {mech }}=\frac{3 R_{1} J}{k_{m} k_{t}}$

Similarly, the electrical time constant in equation (22) becomes as follows

$\tau_{\text {elecl }}=\frac{L_{1}}{3 R_{1}}$

Consider the phase effects, equation (23) becomes as follows

$\tau_{m e c h}=\frac{3 R_{\varphi} J}{\left(k_{m(L-L)} / \sqrt{3}\right) k_{t}}$

Here $k_{m}$ is the phase value of the electromagnetic-force (emf) constant, so $k_{m}$ is equal to as follows

$k_{m}=k_{m(L-L)} / \sqrt{3}$

Also, there is a relationship between $k_{m}$ and $k_{t}$. The electrical power in ideal conditions will be converted into mechanical power, thus equation of powers is given as follows

$\sqrt{3} \times E_{A} \times I=\omega_{m} \times \tau_{m}$

$\frac{E_{A}}{\omega_{m}}=\frac{\tau_{m}}{I} \times \frac{1}{\sqrt{3}}$

Here is a back emf represented with symbol $E_{A}$ and $I$ is the phase current. $\tau$ is the output torque and $\omega_{m}$ is angular velocity of BLDC motor.

$\frac{E_{A}}{\omega_{m}}=\frac{\tau_{m}}{I} \times 0.5774$

$k_{m}=k_{t} \times 0.5774$

Here $k_{m}$ has the units $V \mathrm{sec} / \mathrm{rad} k_{t}$ has the units $\mathrm{Nm} / \mathrm{A}$. Therefore, the equation of BLDC motor can be obtained as follows

$G(s)=\frac{\frac{n}{k_{m}}}{\tau_{\text {mech }} \tau_{\text {elect }} s^{2}+\tau_{\text {mech }} s+n}$ 


\section{Parametric Identification of BLDC motor}

The BLDC motor (ECX SPEED 22 L brushless, BLDC motor $\phi 22 \mathrm{~mm}$ ) is used in this research work.[5] The parameters used in the modelling and simulation are obtained from datasheet of the motor. All the parameters taken from datasheet are presented in the tabular from in table 1 .

\begin{tabular}{|l|l|l|l|}
\hline S No. & Description & Units & Value \\
\hline 1 & Nominal Voltage & $\mathrm{V}$ & 24 \\
\hline 2 & No load Speed & $\mathrm{rpm}$ & 49400 \\
\hline 3 & No load Current & $\mathrm{mA}$ & 432 \\
\hline 4 & Terminal resistance & $\Omega$ & 0.103 \\
\hline 5 & Terminal inductance & $\mathrm{mH}$ & 0.009 \\
\hline 6 & Torque constant & $\mathrm{mNm} / \mathrm{A}$ & 4.63 \\
\hline 7 & Speed constant & $\mathrm{rpm} / \mathrm{V}$ & 2060 \\
\hline 8 & Mechanical time constant & $\mathrm{ms}$ & 1.9 \\
\hline 9 & Rotor inertia & $\mathrm{gcm}{ }^{2}$ & 3.94 \\
\hline
\end{tabular}

Table 1: Parameters found from datasheet of BLDC motor

The gear ratio $\left(n_{2} / n_{1}\right)$ is equal to 5.71 . The $n_{1}$ and $n_{2}$ are 13.07 and 74.62 respectively. Thus

$n=\frac{n_{2}+n_{1}}{n_{1}}=\frac{13.07+74.62}{13.07}$

$n=6.71$

\section{Transfer function of BLDC motor}

Using the table 1 and the mathematical model of BLDC motor in equation (31), the equation (31) becomes as follows

$G(s)=\frac{\frac{n}{k_{m}}}{\tau_{\text {mech }} \tau_{\text {elect }} s^{2}+\tau_{\text {mech }} s+n}$

Now using table1, the values of $\tau_{\text {elect }}$ and $k_{m}$ can be calculated as follows

$$
\begin{aligned}
\tau_{\text {elecl }} & =\frac{L_{1}}{3 R_{1}} \\
\tau_{\text {elecl }} & =\frac{0.009}{3 \times 0.103}=0.0291
\end{aligned}
$$

$$
\begin{aligned}
& \tau_{\text {mech }}=\frac{3 R_{1} J}{k_{m} k_{t}} \\
& k_{m}=\frac{3 \times 0.103 \times 3.94}{0.019 \times 4.63 \times 10^{-3}}=0.01384 \mathrm{~V} \mathrm{sec} / \mathrm{rad}
\end{aligned}
$$

Thus, transfer function of BLDC motor with gear is as follows

$$
G(s)=\frac{484.83}{0.05529 \times 10^{-3} s^{2}+0.0019 s+6.71}
$$

The $G(s)$ derived in the equation (32) is openloop transfer function of the brushless DC maxon motor with gears and load.

\section{Stability Analysis of Open-Loop system}

Found the transfer function $G(s)$ in equation (32), the poles exists at $s=-17.27 \pm i 348.86$ and no zero. These values are plotted on the complex splane in fig. 5 , using an $\times$ for the pole.

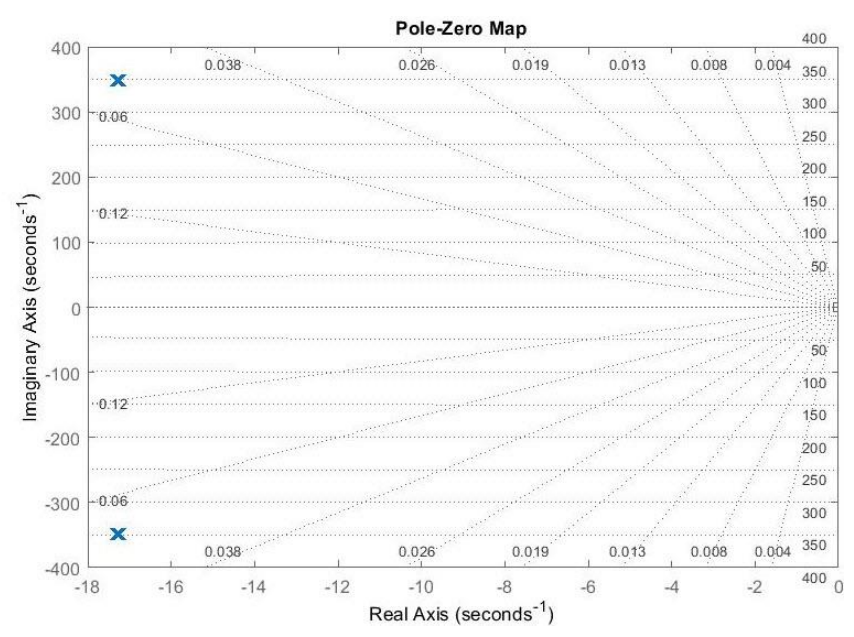

Fig. 5: Pole Zero plot of uncompensated system

Two Poles are complex, and they lie at $-17.27 \pm i 348.86$ as shown in fig. 5. Thus, the system under consideration has underdamped response. The natural response of this system has damped sinusoid with an exponential envelop, whose time constant is equal to the reciprocal of the pole's real part. Real part of the pole matches the exponential decay frequency of sinusoid's amplitude, while the imaginary part of the pole matches the frequency of the sinusoidal oscillation. The radian frequency of the sinusoid, the damped 
frequency of oscillation, is equal to imaginary part of the poles, or in the language of mathematics

Poles: 2 complex at $-\sigma_{d} \pm i \omega_{d}$

$c(t)=A e^{-\sigma_{d} t} \cos \left(\omega_{d} t-\phi\right)$

Here $\sigma_{d}$ exponential frequency for the damping and $\omega_{d}$ is damped frequency of oscillation. Hence -17.27 is the exponential frequency for the damping. It is also reciprocal of the time constant of the decay of the oscillations.

\section{Rootlocus of Open-Loop System}

Sketching the Root locus of a

$G(s)=\frac{484.83}{(s+17.27+i 348.86)(s+17.27-i 348.86)}$

Apply the basic rules of rootlocus as follows

a. No. of Branches $=2$

b. Symmetrical with respect to the real axis.

c. Starting Point/s: (Open-Loop Poles) s = -

$17.27+i 348.86,-17.27-i 348.86$

Ending Point/s: (Open-Loop Zeros) s $=\infty$, $\infty$

d. Behavior at Infinity: (Asymptotes)

Number of Asymptotes $=\#$ finite OL poles -

\# finite OL zeros

Number of Asymptotes $=2-0$

Number of Asymptotes $=2$

e. Real-Axis Intercept (centre of Asymptotes), $\sigma a:$

$\sigma_{a}=\frac{\sum \text { finite } O L \text { poles }-\sum \text { finite } O L \text { zeros }}{\# \text { finite } O L \text { poles }-\# \text { finite } O L \text { zeros }}$

$\sigma_{a}=\frac{-17.27+i 348.86-17.27-i 348.86-0}{2-0}$

$$
=-17.27
$$

Angle of Asymptotes, $\Theta$ :

$$
\begin{aligned}
& \Theta=\frac{(2 k+1) 180}{\text { \#finite OL poles - \#finite OL zeros }} \\
& \Theta=90^{\circ}, k=0 \\
& \Theta=270^{\circ}, k=1
\end{aligned}
$$

f. Real-Axis Breakaway and Break-In Points

Using Transition Method:

$$
\begin{aligned}
& \sum_{1}^{m} \frac{1}{\sigma+z_{i}}=\sum_{1}^{n} \frac{1}{\sigma+p_{i}} \\
& \frac{1}{\sigma+17.27+i 348.86}+\frac{1}{\sigma+17.27-i 348.86}=0 \\
& \sigma=-17.27
\end{aligned}
$$

Since, -17.27 is at the real axis segment (just a point) and -17.27 is a breakaway point.

Using Differentiation:

$$
\begin{aligned}
& \frac{K}{(s+17.27+i 348.86)(s+17.27-i 348.86)} \\
& =-1 \\
& K=-s^{2}-34.54 s-122001.055 \\
& K=-\sigma^{2}-34.54 \sigma-122001.055 \\
& \frac{d K}{d \sigma}=-2 \sigma-34.54=0 \\
& \sigma=-17.27
\end{aligned}
$$

Same Analysis as above!!!

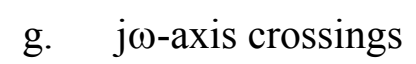

Routh Table:

\begin{tabular}{|l|l|l|l|}
\hline$s^{2}$ & 1 & $1220001.55+484.83 \mathrm{~K}$ & 0 \\
\hline $\mathrm{s}^{1}$ & 34.54 & 0 & 0 \\
\hline $\mathrm{s}^{0}$ & $1220001.55+484.83 \mathrm{~K}$ & & 0 \\
\hline
\end{tabular}

Force a row of zeros at $\mathrm{s}^{0}$ : thus, $1220001.55+484.83 \mathrm{~K}=0$, thus $\mathrm{K}=-251.64$

Generate polynomial at $\mathrm{s}^{1}$ row: $34.54 \mathrm{~s}=0$, Hence $s=0$. The root locus will not cross the $j \omega$ axis because $\mathrm{K}$ cannot be negative. For $K \geq 0$ the system is stable.

\section{Simulation results}

Notice that the second order system with no zero. The rootlocus of the system is shown in fig. 6 and clearly shows all the above 7 points presented in previous section. The transfer function of the system presented in equation (32) and rootlocus presented in fig. 6. The step response of the system presented in fig. 7, the settling time, peak time and steadystate error obtained from fig. 7. The settling time $0.226 \mathrm{sec}$, peak time $0.00899 \mathrm{sec}, \% \mathrm{OS} 85.6 \%$ and 
steady state error 71.3 (system behaviour with respect to step input). Breakaway point lies at 17.27, where the gain reaches a peak.

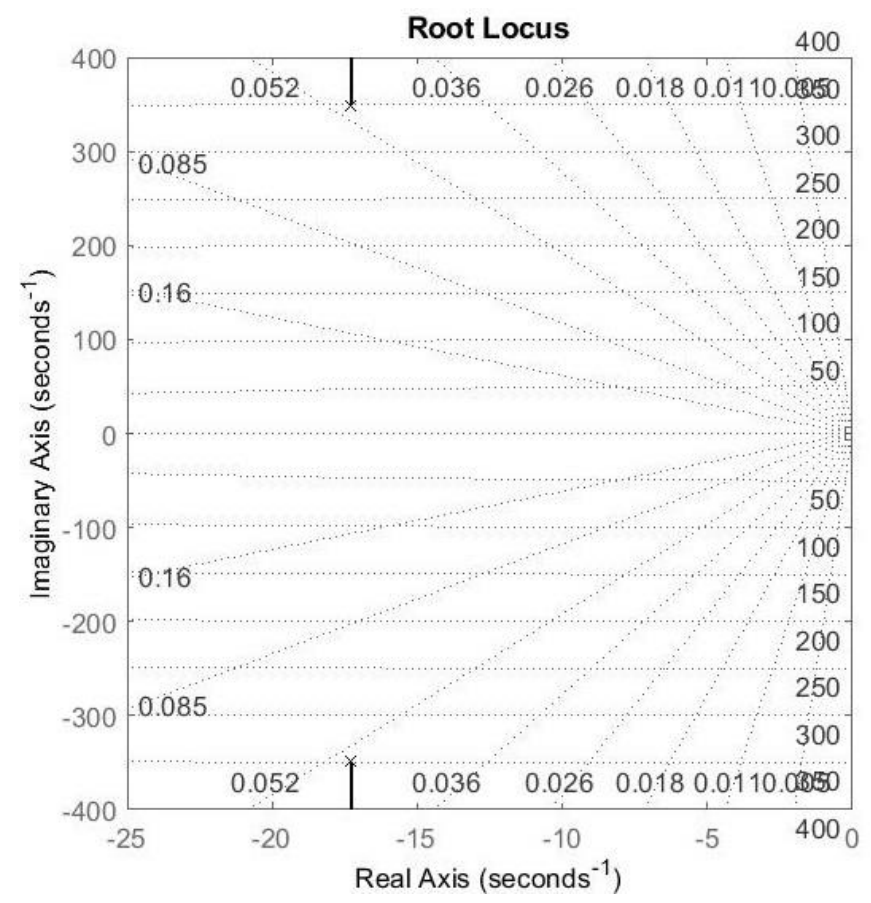

(a)

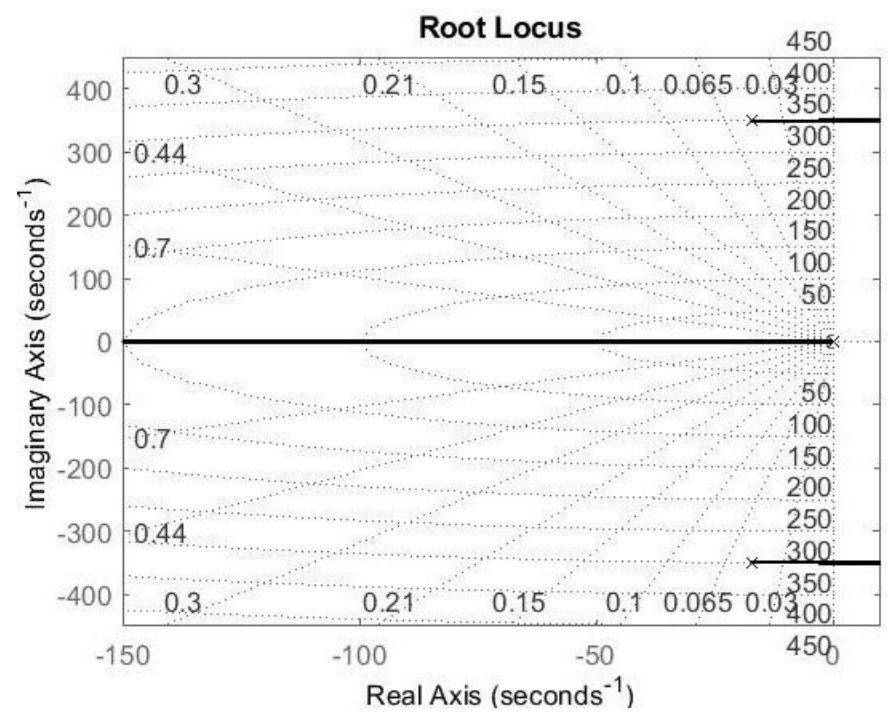

(b)

Fig. 6: (a) Rootlocus of uncompensated system (Transfer function between Angular Speed and input voltage) (b) Rootlocus of uncompensated system (Transfer function between Angular Displacement and input voltage)

The plot in fig. 7 is between angular velocity and time. Step response of the system is as follow

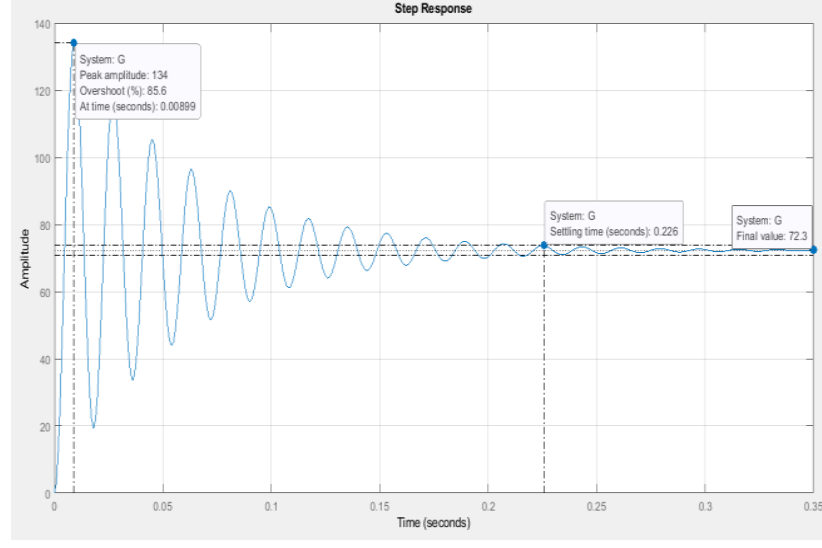

(a)

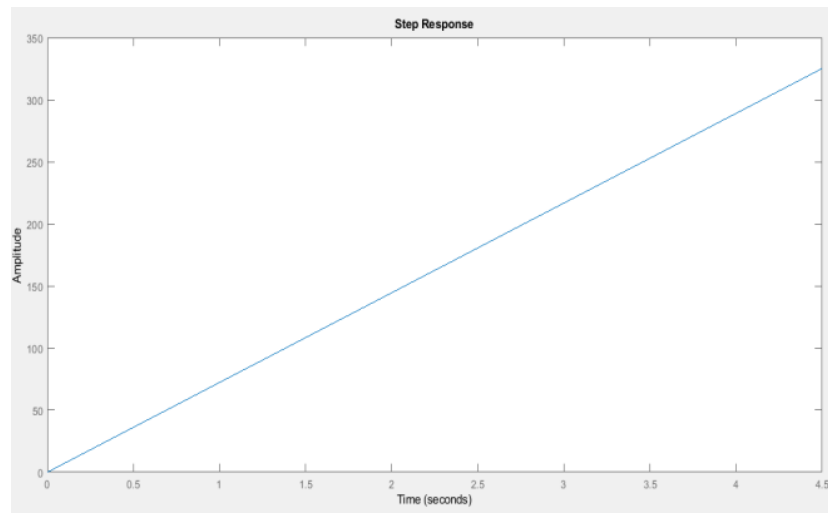

(b)

Fig. 7: (a) Step response of uncompensated system (Angular Speed vs Time) (b) Step response of uncompensated system (Angular Displacement vs Time)

The step response of system shows that large steady state error and settling time 0.226 seconds, peak time 0.00899 and percentage overshoot is very high $85.6 \%$ in fig. 7(a). In fig. 7(b) the parameters are not measurable. To reduce the percentage overshoot the state feedback controller is presented in next section.

\section{Controller design for Phase-variable form}

The rootlocus technique is not able to reduce overshoot and steady state error of the system. Then applied the state feedback controller. The transfer function between the angular position and supply voltage is as follows

$$
G(s)=\frac{484.83}{0.05529 \times 10^{-3} s^{3}+0.0019 s^{2}+6.71 \mathrm{~s}}
$$


Using the above equation, formed a Laplace equation as follows

$0.05529 \times 10^{-3} s^{3} \theta(s)+0.0019 s^{2} \theta(s)+$ $6.71 \mathrm{~s} \theta(s)=484.83 \mathrm{~V}_{s}(s)$

Take the inverse Laplace of the above equation

$$
0.05529 \times 10^{-3} \frac{d^{3} \theta}{d t^{3}}+0.0019 \frac{d^{2} \theta}{d t^{2}}+6.71 \frac{d \theta}{d t}=
$$$$
484.83 \mathrm{v}_{S}
$$

An easy method to choose the state variables are to select the output, $\theta$ and its $(n-1)$ derivatives on the state variables. This method is called phasevariable form. Choose the state variables, $x_{1}$ and equation are as follows

$$
\begin{aligned}
& x_{1}=\theta \\
& x_{2}=\dot{\theta} \\
& x_{3}=\ddot{\theta}
\end{aligned}
$$

and differentiate both sides yield

$$
\begin{aligned}
& \dot{x}_{1}=\dot{\theta} \\
& \dot{x}_{2}=\ddot{\theta} \\
& \dot{x}_{3}=\ddot{\theta}
\end{aligned}
$$

and substituting the definitions of equations, the state equations are evaluated as follows

$\dot{x}_{1}=x_{2}$

$\dot{x}_{2}=x_{3}$

$\dot{x}_{3}=-121360.1 x_{2}-34.36 x_{3}+8768855.13 \mathrm{v}_{s}$

The transfer function of the system can be written as in fig. 8 .

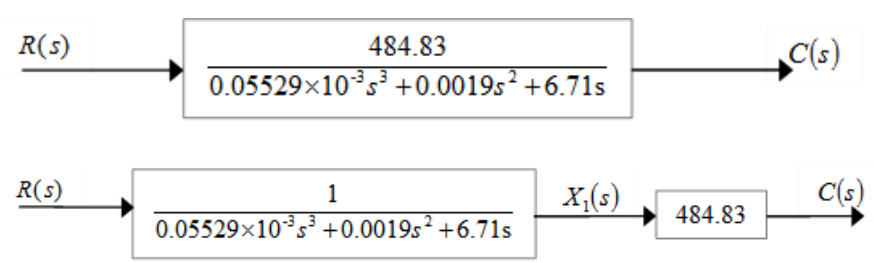

Fig. 8: Transfer function in cascade form

Thus, the state space of the system is as follows

$$
\left[\begin{array}{l}
\dot{x}_{1} \\
\dot{x}_{2} \\
\dot{x}_{3}
\end{array}\right]=\left[\begin{array}{ccc}
0 & 1 & 0 \\
0 & 0 & 1 \\
0 & -121360.1 & -34.36
\end{array}\right]\left[\begin{array}{l}
x_{1} \\
x_{2} \\
x_{3}
\end{array}\right]+\left[\begin{array}{l}
0 \\
0 \\
1
\end{array}\right] r(39)
$$

Equation (39) is phase-variable form of state equations. The form is easily recognized by unique pattern of 1 's and 0 's and negation of the coefficients of the differential equations written in reverse order in the last row of the system matrix. According to the above fig. 8 , the output equation is as follows

$$
y=\left[\begin{array}{lll}
8768855.13 & 0 & 0
\end{array}\right]\left[\begin{array}{l}
x_{1} \\
x_{2} \\
x_{3}
\end{array}\right]
$$

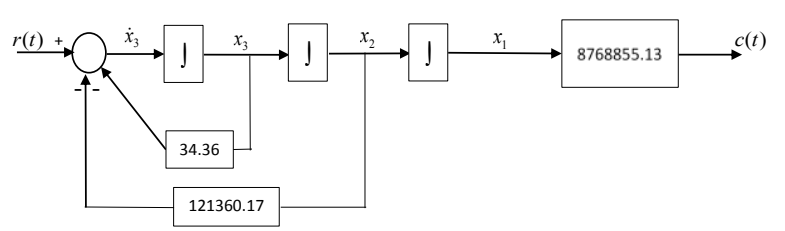

Fig. 9: state-space representation of a system

Thus

$$
\begin{aligned}
& (A-B K)=\left[\begin{array}{ccc}
0 & 1 & 0 \\
0 & 0 & 1 \\
-k_{1} & -\left(121360.17+k_{2}\right) & -\left(34.36+k_{3}\right)
\end{array}\right] \\
& \operatorname{det}(s I-(A-B K))=\left|\begin{array}{ccc}
s & -1 & 0 \\
0 & s & -1 \\
k_{1} & \left(121360.17+k_{2}\right) & s+\left(34.36+k_{3}\right)
\end{array}\right| \\
& \operatorname{det}(s I-(A-B K))=s^{3}+\left(34.36+k_{3}\right) s^{2}+\left(121360.17+k_{2}\right) s+k_{1}=0
\end{aligned}
$$
data

The desired equation is form using the following

$\% O S=10 \%$ and $T_{S}=0.2 \mathrm{sec}$

The $\xi$ calculated from given $\% \mathrm{OS}$, the value of $\xi$ corresponding to allowed percentage overshot is 0.5912 . The $\omega_{n}$ calculated from given settling time $0.2 \mathrm{sec}$, the value of $\omega_{n}$ is $33.83 \mathrm{rad} / \mathrm{s}$. The second order equation is as follows

$$
s^{2}+2 \zeta \omega_{n} s+\omega_{n}^{2}=s^{2}+40 s+1144.44
$$

Since system has no zeros, assume no zeros for closed-loop system and augment equation (42), with third pole $(s+100)$ which has a real part greater than five times that of the desired dominant second order 
poles. The desired third order closed loop system characteristic equation is formed

$$
\begin{aligned}
& (s+100)\left(s^{2}+40 s+1144.44\right)=0 \\
& s^{3}+140 s^{2}+5144.44 s+114444=0
\end{aligned}
$$

By comparing the coefficients of equation (41) and (43), got the following result

$$
k_{3}=105.64, k_{2}=-116215.73, k_{1}=114444
$$

The state equations for the closed-loop system can be written by inspection method

$$
\begin{aligned}
& \dot{x}=(A+B K) x+B r \\
& y=C x
\end{aligned}
$$

Each state variable is then fed back to the system is input through a given $k_{i}$ as shown in fig. 10.

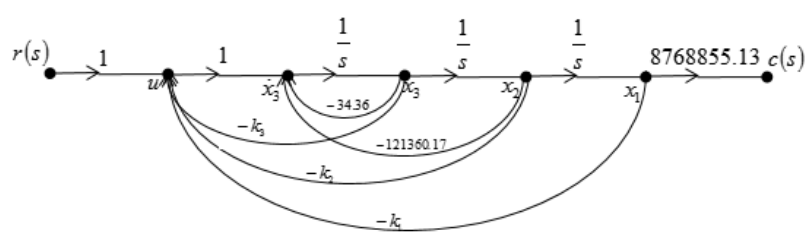

Fig. 10: Signal flow graph of system with state variable feedback

Using the equation (45) with equations (44) and (40), the system matrix $(A-B K)$, for the closedloop system is

$$
(A-B K)=\left[\begin{array}{ccc}
0 & 1 & 0 \\
0 & 0 & 1 \\
-114444 & -5144.44 & -140
\end{array}\right]
$$

Thus, the state-space model of the system in phase variable form is as follows

$$
\begin{aligned}
& \dot{x}=\left[\begin{array}{ccc}
0 & 1 & 0 \\
0 & 0 & 1 \\
-114444 & -5144.44 & -140
\end{array}\right] x+\left[\begin{array}{l}
0 \\
0 \\
1
\end{array}\right] r \\
& y=\left[\begin{array}{lll}
8768855.13 & 0 & 0
\end{array}\right] x
\end{aligned}
$$

The transfer function of the system is

$$
T(s)=\frac{8768855.13}{s^{3}+140 s^{2}+5144.44 s+114444}
$$

The settling time is 0.186 seconds, peak time is 0.127 seconds, steady state error is 76.6 and percentage overshoot is $9.3 \%$. This data is found by taking the step response of equation (47), result is plotted in the fig. 11. The equation (47) is the transfer function of controlled system as in fig. 10.

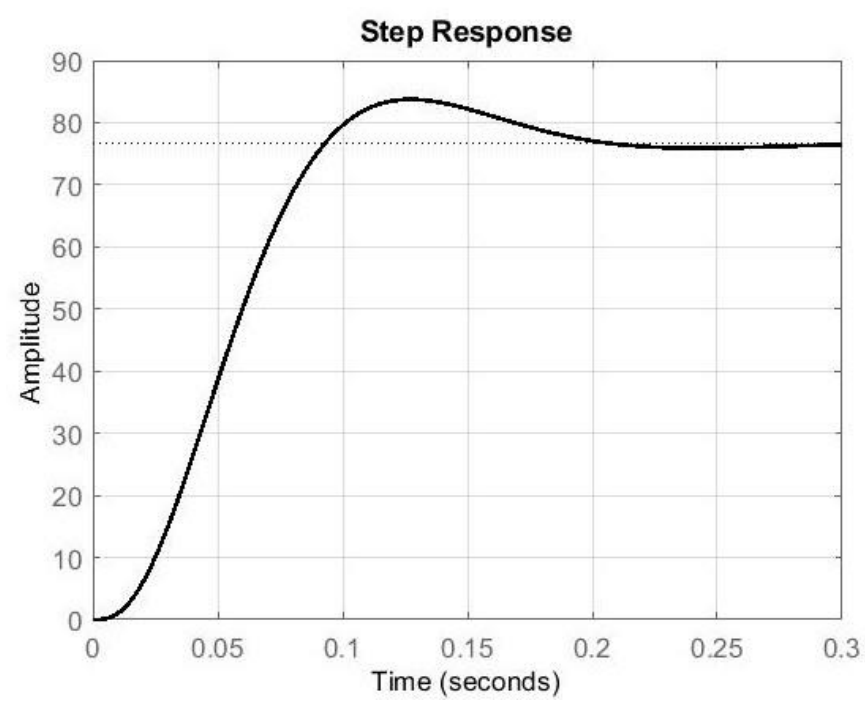

Fig. 11: Step response of compensated system

Since the steady-state response approaches 76.6 instead of unity, there is a large steady state error. Design technique to reduce this error is presented in next section.

\section{Integral control for steady-state error design}

The previously designed controller is shown inside the dashed box. A feedback path has been added to form the error, e, which is fed forward to the controlled system via an integrator. Design of controller has been discussed in detail in [7].

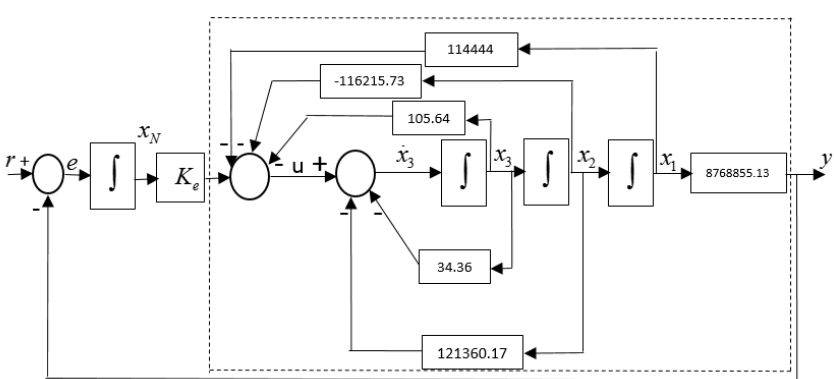

Fig. 12: Integral control for steady-state error design 
The controllability and observability of a the (39) are determined. The determinant of $C_{m}$ (controllability matrix) is equal to -1 . Since the determinant is not zero the $3 \times 3$ matrix is nonsingular and rank of $C_{m}$ is 3 . Conclusion the system is controllable since the rank of $C_{m}$ equals the system order.

The integrator increases the system type and reduces the steady state error to zero. The state feedback controller has reduced \%OS and integral shall reduce the steady state error to zero for step input. An additional state variable $x_{N}$ has been added at the output of the leftmost integrator as shown in the fig. 12. The error is the derivative of this variable. Equations (46) can be written as augmented vectors and matrices. Hence

$$
\begin{aligned}
& {\left[\begin{array}{l}
\dot{x}_{1} \\
\dot{x}_{2} \\
\dot{x}_{3} \\
\dot{x}_{N}
\end{array}\right]=} \\
& {\left[\left(\left[\begin{array}{lll}
0 & 1 & 0 \\
0 & 0 & 1 \\
0 & -121360.17 & -34.36
\end{array}\right]-\left[\begin{array}{l}
0 \\
0 \\
1
\end{array}\right]\left[\begin{array}{lll}
k_{1} & k_{2} & k_{3}
\end{array}\right]\right)\left[\begin{array}{l}
0 \\
0 \\
1
\end{array}\right] k_{e}\left[\begin{array}{l}
x_{1} \\
x_{2} \\
x_{3} \\
x_{N}
\end{array}\right]+\right.} \\
& {\left[\begin{array}{l}
0 \\
0 \\
0 \\
1
\end{array}\right] r} \\
& y=\left[\begin{array}{lllll}
87688555.13 & 0 & 0 & 0
\end{array}\right] x
\end{aligned}
$$

Thus, the system type has been increased and characteristic equation associated with equation (48) will be used to design $K$ and $k_{e}$ to yield the desired transient response. The integral controlled system equations are as follow

$\left[\begin{array}{c}\dot{x}_{1} \\ \dot{x}_{2} \\ \dot{x}_{3} \\ \dot{x}_{N}\end{array}\right]=\left[\begin{array}{cccc}0 & 1 & 0 & 0 \\ 0 & 0 & 1 & 0 \\ -k_{1} & -\left(121360.17+k_{2}\right) & -\left(34.36+k_{3}\right) & k_{e} \\ -8768855.13 & 0 & 0 & 0\end{array}\right]\left[\begin{array}{c}x_{1} \\ x_{2} \\ x_{3} \\ x_{N}\end{array}\right]+\left[\begin{array}{l}0 \\ 0 \\ 0 \\ 1\end{array}\right] r$

The characteristic polynomial for the system of equation (50) is as follows

$$
\begin{aligned}
& s^{4}+\left(34.36+k_{3}\right) s^{3}+\left(121360.17+k_{2}\right) s^{2}+ \\
& k_{1} s+8768855.13 k_{e}=0
\end{aligned}
$$

The desired equation is

$$
\begin{aligned}
& (s+100)^{2}\left(s^{2}+40 s+1144.44\right)=0 \\
& s^{4}+240 s^{3}+19144.44 s^{2}+628888 s+11444400=0
\end{aligned}
$$

By comparing the equation (51) and (52), the values of gains are found

$k_{3}=205.64, k_{2}=19144.44, k_{1}=628888, k_{e}=1.305$

The equations (48) and (49) become

$$
\left[\begin{array}{l}
\dot{x}_{1} \\
\dot{x}_{2} \\
\dot{x}_{3} \\
\dot{x}_{N}
\end{array}\right]=\left[\begin{array}{cccc}
0 & 1 & 0 & 0 \\
0 & 0 & 1 & 0 \\
-628888 & -19144.44 & -240 & 1.305 \\
-8768855.13 & 0 & 0 & 0
\end{array}\right]\left[\begin{array}{c}
x_{1} \\
x_{2} \\
x_{3} \\
x_{N}
\end{array}\right]+\left[\begin{array}{l}
0 \\
0 \\
0 \\
1
\end{array}\right] r
$$

$$
y=\left[\begin{array}{llll}
8768855.13 & 0 & 0 & 0
\end{array}\right] x
$$

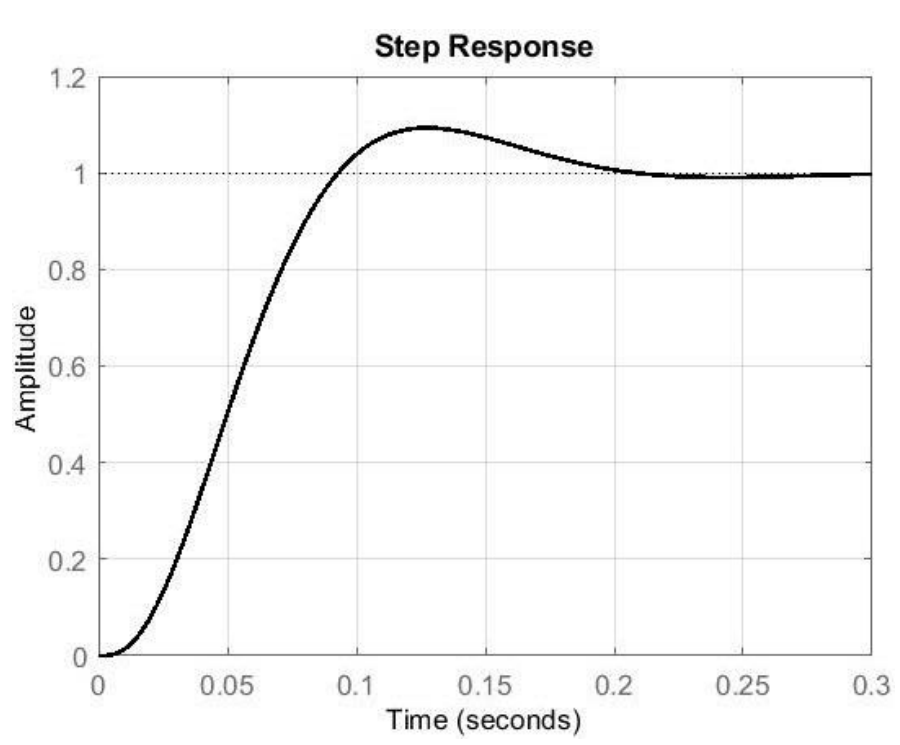

Fig. 13: The step response of controlled system

The settling time is 0.197 seconds, peak time is 0.139 seconds, steady state error is 0 and percentage overshoot is $8.64 \%$. This data is found by taking the step response of transfer function obtained from equations (53-54), result is plotted in the fig. 13.

\section{Conclusion and results}

The State feedback controller with integral control and State feedback controller without integral control are presented in this paper. In the section 9 state feedback controller was applied and it was desired that the output response should lie a certain percentage overshoot with specified settling time. As a conclusion, the state feedback controller with integral control is better than the state feedback controller without the integral control, thus state feedback controller with integral controller structures can be further be implemented. The rootlocus technique was not able to control the 
system as discussed in the section 8. The comparison of these three techniques is presented in table 2 .

\begin{tabular}{|l|l|l|l|}
\hline $\begin{array}{l}\text { Technique / } \\
\text { Parameters }\end{array}$ & $\begin{array}{l}\text { Rootlocus } \\
\text { technique }\end{array}$ & $\begin{array}{l}\text { State } \\
\text { feedback } \\
\text { Controller }\end{array}$ & $\begin{array}{l}\text { Integral } \\
\text { control for } \\
\text { steady- } \\
\text { state error }\end{array}$ \\
\hline Settling time & - & $\begin{array}{l}0.186 \\
\text { Seconds }\end{array}$ & $\begin{array}{l}0.197 \\
\text { Seconds }\end{array}$ \\
\hline Peak time & - & $\begin{array}{l}0.127 \\
\text { Seconds }\end{array}$ & $\begin{array}{l}0.139 \\
\text { Seconds }\end{array}$ \\
\hline $\begin{array}{l}\text { Percentage } \\
\text { Overshoot }\end{array}$ & - & $9.30 \%$ & $8.64 \%$ \\
\hline $\begin{array}{l}\text { Steady State } \\
\text { error }\end{array}$ & - & 76.6 & 0 \\
\hline
\end{tabular}

Table 2: Comparison of results from the 3 techniques

The rootlocus technique is failed to control the $\% \mathrm{OS}$ and steady state error. The state feedback controller controlled the percentage overshoot, but steady state error was very high. The integral control applied for steady-state error and integral control successfully controlled the steady-state error.

\section{Reference:}

[1] Imran S. Sarwar, "System modelling, stability analysis and motion control using a novel technique", International Journal of Scientific \& Engineering Research, ISSN 2229-5518, Volume 10, Issue 7, July 2019, pp. 611-618.

[2] Robert H. Bishop, "The Mechatronics Handbook", CRC press, 2002, pp. 525-535.

[3] Padmaraja Yedamale, "Brushless DC motor fundamentals", Microchip technology incorporated, 2003.

[4] Åstrom k, Hagglund T, "PID Controllers: Theory, Design, and Tuning", Instrument Society of America, 2nd edition, 1994.

[5] Datasheet of Maxon ECX Speed 22L brushless, BLDC motor $\emptyset 22 \mathrm{~mm}$.

[6] Nikola Milivojevic, Yusuf Gurkaynak, YoungJoo Lee,"Stability Analysis of FPGA-Based Control of Brushless DC Motors and Generators Using Digital PWM Technique", IEEE Transactions on Industrial Electronics, vol. 59, no. 1, Jan 2012.

[7] Norman S. Nise, "Control Systems Engineering", John Wiley \& Sons, 2004, pages 770-800.

[8] Imran S. Sarwar, Javaid Iqbal, Afzaal M. Malik, "Modelling and motion control of a mechatronics system using BGM with intelligent controllers", International Journal of the federation of European Simulation Societies, Simulation Modelling Practice and Theory, Elsevier Science, ISSN: 1569-190X, doi: 10.1016/j.simpat.2010.04.012, Volume 18, Issue 9, Oct 2010, pp. 1253-1265.

[9] Dan Liu, Yurong Liu, Fuad E. Alsaadi, "A new framework for output feedback controller design for a class of discrete-time stochastic nonlinear system with quantization and missing measurement", International Journal of General Systems, Vol. 45, No. 5, 2016, 517531

[10] C. Thammarat and D. Puangdownreong, Design of Fractional Order PID Controller for Induction Motor Speed Control System by Cuckoo Search, International Journal of Circuits, Systems and Signal Processing, Volume 13, 2019, pp. 92-96.

[11] Jesús U. Liceaga-Castro, Irma I. Siller-Alcalá, Real Time PI Speed Control of a Series DC Motor, International Journal of Circuits, Systems and Signal Processing, Volume 13, 2019, pp. 373-378.

[12] https://www.motioncontrolonline.org/blogarticle.cfm/Brushed-DC-Motors-Vs-BrushlessDC-Motors/24

\section{Creative Commons Attribution License 4.0 (Attribution 4.0 International, CC BY 4.0)}

This article is published under the terms of the Creative Commons Attribution License 4.0

https://creativecommons.org/licenses/by/4.0/deed.en_US 